\title{
Phenomena induced by powerful HF pumping towards magnetic zenith with a frequency near the F-region critical frequency and the third electron gyro harmonic frequency
}

\author{
N. F. Blagoveshchenskaya ${ }^{1}$, H. C. Carlson ${ }^{2}$, V. A. Kornienko ${ }^{1}$, T. D. Borisova ${ }^{1}$, M. T. Rietveld ${ }^{3}$, T. K. Yeoman $^{4}$, and \\ A. Brekke ${ }^{5}$ \\ ${ }^{1}$ Arctic and Antarctic Research Institute, St. Petersburg, Russia \\ ${ }^{2}$ European Office of Aerospace Research and Development, UK \\ ${ }^{3}$ EISCAT Scientific Association, Ramfjordbotn, Norway \\ ${ }^{4}$ Department of Physics and Astronomy, University of Leicester, LEI 7RH, UK \\ ${ }^{5}$ University of Troms $\varnothing$, Troms $\varnothing$, Norway
}

Received: 5 December 2007 - Revised: 1 December 2008 - Accepted: 1 December 2008 - Published: 8 January 2009

\begin{abstract}
Multi-instrument observational data from an experiment on 13 October 2006 at the EISCAT/HEATING facility at Troms $\varnothing$, Norway are analysed. The experiment was carried out in the evening hours when the electron density in the F-region dropped, and the HF pump frequency $f_{H}$ was near and then above the critical frequency of the F2 layer. The distinctive feature of this experiment is that the pump frequency was just below the third electron gyro harmonic frequency, while both the HF pump beam and UHF radar beam were directed towards the magnetic zenith (MZ). The HF pump-induced phenomena were diagnosed with several instruments: the bi-static HF radio scatter on the LondonTroms $\varnothing$-St. Petersburg path, the CUTLASS radar in Hankasalmi (Finland), the European Incoherent Scatter (EISCAT) UHF radar at Troms $\varnothing$ and the Troms $\varnothing$ ionosonde (dynasonde). The results show thermal electron excitation of the HF-induced striations seen simultaneously from HF bi-static scatter and CUTLASS radar observations, accompanied by increases of electron temperature when the heater frequency was near and then above the critical frequency of the F2 layer by up to $0.4 \mathrm{MHz}$. An increase of the electron density up to $25 \%$ accompanied by strong HF-induced electron heating was observed, only when the heater frequency was near the critical frequency and just below the third electron gyro harmonic frequency. It is concluded that the combined effect of upper hybrid resonance and gyro resonance at the same altitude gives rise to strong electron heating, the excitation of
\end{abstract}

Correspondence to:

N. F. Blagoveshchenskaya

(nataly@aari.nw.ru) striations, HF ray trapping and extension of HF waves to altitudes where they can excite Langmuir turbulence and fluxes of electrons accelerated to energies that produce ionization.

Keywords. Ionosphere (Active experiments) - Radio science (Nonlinear phenomena)

\section{Introduction}

It is well known that intense HF radio waves transmitted from high-power ground-based HF heating facilities strongly modify the ionospheric plasma. The excitation of artificial small-scale field-aligned irregularities or striations (Minkoff et al., 1974; Djuth et al., 1985; Blagoveshchenskaya et al., 1999, 2006b), HF-induced electron heating (Rietveld et al., 2003) and airglow (Brandstrom et al., 1999; Pedersen and Carlson, 2001; Kosch et al., 2002), anomalous absorption (Robinson, 1989) and other phenomena occur at the upper hybrid resonance altitude in HF heating experiments when O-mode polarized HF pump waves reach the ionospheric reflection height. An O-mode HF pump wave couples through striations into electrostatic (upper hybrid) waves at the upper-hybrid resonance altitude, which is below the reflection height of the heating wave. Upper hybrid waves propagate in a direction near perpendicular to the magnetic field and their energy dissipation heats the electrons. Through thermal instabilities, these waves can excite artificial field-aligned irregularities (AFAIs) which can trap the exciting upper hybrid field. Theoretical work undertaken in the 1970s indicated that the thermal parametric instability

Published by Copernicus Publications on behalf of the European Geosciences Union. 
(Grach and Trakhtengerts, 1976) and resonance instability (Vas'kov and Gurevich, 1976) play important roles in the generation of artificial field-aligned irregularities, or striations. More recent theoretical studies of non-linear stabilization of the striations (Gurevich et al., 1995), the self-focusing of the HF pump wave caused by the density depletions within the striations (Gurevich et al., 2001), and the excitation of density and/or temperature-gradient-driven instabilities such as a drift wave (Franz et al., 1999) have also detailed various generation mechanisms. Striations are generated near the upper hybrid resonance (UHR) altitude, where the heater frequency is $f_{H}^{2}=f_{\mathrm{UHR}}^{2}=f_{p}^{2}+f_{c e}^{2}$, where $f_{p}$ is the local plasma frequency and $f_{c e}$ is the electron gyrofrequency. The UHR height is several kilometers below the reflection level of the HF pump wave. Radio wave HF pump-induced ionospheric phenomena occurring near electron gyroharmonics have attracted considerable interest especially as double- vs. singleresonance phenomena.

Electron acceleration above $10 \mathrm{eV}$ is well established, and recent measurements of blue emissions at $427.8 \mathrm{~nm}$ from $\mathrm{N}_{2}^{+}$in artificial aurora at high latitudes (Holma et al., 2006; Gustavsson et al., 2006) are direct evidence of some flux of electrons with energies above $18 \mathrm{eV}$, producing HF-enhanced ionization. Spatio-temporal evolution of HF-induced phenomena near the fourth electron gyroharmonic (Ashrafi et al., 2006, 2007) is indicative of a descent in altitude of EISCAT UHF ion line enhancements and optical emissions, both accompanied by pump-induced variations in electron density.

EISCAT/HEATING experiments at Troms $\varnothing$ have shown AFAIs excited in the F-region as well as in the auroral Eregion when the pump frequency exceeded the critical frequency, as observed by an ionosonde located near the HF heating facility. Djuth et al. (1985) found from VHF radar observations during Troms $\varnothing$ HF heating experiments, that the generation of striations in the auroral E-region was possible when the heater frequency, $f_{H}$, exceeded the critical frequency $f o$ Es by $0.2 \mathrm{MHz}$. The same result was obtained by Blagoveshchenskaya et al. (1999, 2006a) when strong heaterinduced striations were observed in the auroral E-region with bi-static HF radio scatter. Striations have also been observed from Troms $\varnothing$ HF heating experiments in the night-side Fregion of the auroral ionosphere when $f o \mathrm{~F} 2$ drops below the heater frequency by up to $0.5 \mathrm{MHz}$ (Blagoveshchenskaya et al., 2006b). In all these studies the condition of the auroral ionosphere was monitored by ionosonde data. It was found that despite the fact that the HF pump frequency exceeded $f o \mathrm{~F} 2$ ( $f o \mathrm{Es}$ ), it was comparable to the maximum upper hybrid frequency. Observations of airglow at $630 \mathrm{~nm}$ (red line) and $557.7 \mathrm{~nm}$ (green line) during the HF ionospheric modification experiments at the HAARP heating facility have shown HF-induced green and red lines at the magnetic zenith (MZ) to persist after the critical frequency $f_{o} \mathrm{~F} 2$ dropped below the heater frequency (Pedersen et al., 2003). In the same study it was mentioned that the brightest emissions had a slight tendency to occur very near the critical frequency of the F2 layer, but all emissions cut off sharply at about $0.5 \mathrm{MHz}$ above $f o \mathrm{~F} 2$. Again here the status of the ionosphere was estimated from an ionosonde located at the HAARP site. Mishin et al. (2005) proposed a scenario for the HF heater-induced phenomena at magnetic zenith in the underdense ionosphere when $f o \mathrm{~F} 2$ dropped below the heater frequency, but HF-induced airglow at green and red lines remained. He explained this feature in terms of strong turbulence at magnetic zenith, with the oscillating two-stream instability (OTSI) of upper hybrid waves as the primary source of Langmuir waves. Note that ionosondes provide information about the status of the ionosphere above the heating facility as a whole, but they cannot reproduce the peculiarities in the different parts of the heated volume with high temporal resolution. Hence there is a need to compare data from the dynasonde (Rietveld et al., 2008) and the EISCAT UHF radar directed towards magnetic zenith.

In this paper we present multi-instrument experimental results from an experiment on 13 October 2006 at the EISCAT/HEATING facility at Troms $\varnothing$, Norway, where the HFpump beam was directed towards the magnetic zenith (MZ). In the course of the experiment the electron density in the Fregion dropped, and the heater frequency was near and then above the critical frequency of F2 layer. Of special importance to this experiment is that the pump frequency was just below the third electron gyro harmonic frequency. We examine the behavior of the HF-induced striations from bi-static HF radio scatter on the London-Troms $\emptyset$-St. Petersburg path and from CUTLASS radar in Hankasalmi (Finland). Further, we analyze in detail the distinctive features in the behavior of ionospheric plasma parameters, particularly the electron density $N_{e}$ and electron temperature $T_{e}$, from the European Incoherent Scatter (EISCAT) UHF radar at Troms $\varnothing$, pointing in the MZ. Finally, we discuss and explain the results obtained.

\section{Experimental arrangement}

The experiment reported here was conducted on 13 October 2006 from 15:00 to 19:00 UT. The EISCAT HF heating facility (Rietveld et al., 1993) located near Troms $\varnothing$ in Northern Norway (geographical coordinates $69.6^{\circ} \mathrm{N}, 19.2^{\circ} \mathrm{E}$; magnetic dip angle $I=78^{\circ}$ ) was used to perturb the ionosphere in the high-latitude F-region. The heating facility was operating at $4040 \mathrm{kHz}$, in O-mode polarization, with a modulation cycle of $2 \mathrm{~min}$ on/ $2 \mathrm{~min}$ off. The phased array 2 was used, resulting in an effective radiated power (ERP) of $190 \mathrm{MW}$. The HF heater antenna beam was tilted $12^{\circ}$ to the south of zenith, thus allowing HF pumping in the field-aligned direction (magnetic zenith, MZ).

The HF heating facility at Troms $\varnothing$ is located adjacent to the EISCAT UHF incoherent radar at $930 \mathrm{MHz}$ (Rishbeth and van Eyken, 1993). In the course of the experiment the UHF radar antenna was directed towards magnetic zenith. 
Bi-static HF Doppler radio scatter observations were carried out on the London-Troms $\varnothing$-St. Petersburg path at an operational frequency of $17640 \mathrm{kHz}$. In accordance with the Bragg condition, the HF bi-static backscatter is sensitive to small-scale irregularities having spatial sizes of the order of $9 \mathrm{~m}$ across the geomagnetic field. The diagnostic transmitter is located near London $\left(52^{\circ} \mathrm{N}, 0^{\circ} \mathrm{E}\right)$ at a great circle distance of $\sim 2200 \mathrm{~km}$ from Troms $\varnothing$. The reception of the diagnostic waves scattered from field-aligned irregularities over Troms $\varnothing$ was made with a Doppler spectral method in St. Petersburg $\left(60^{\circ} \mathrm{N}, 30^{\circ} \mathrm{E}\right)$ at a distance of $\sim 1200 \mathrm{~km}$ (with a double rhombic receiving antenna directed towards Troms $\varnothing$ ). The spectral processing was carried out by using a windowed (Hanning) fast Fourier transformation (FFT). In the course of the Troms $\varnothing$ experiment described here, a sampling rate of $102 \mathrm{~Hz}$ allowed a spectral analysis bandwidth of $51 \mathrm{~Hz}$. A specified number of 512 FFT coefficients provided a frequency resolution of $0.1 \mathrm{~Hz}$. Each segment used for the FFT was overlapped by $50 \%$, which yielded the production of a Doppler spectrum every $5 \mathrm{~s}$. The mechanism of bi-static scatter is very similar to direct backscatter, but with the transmitter and receiver at different locations. The azimuth angle between the incident and scattered wave vectors is about $120^{\circ}$ on the London-Troms $\varnothing$-St. Petersburg path.

Simultaneous CUTLASS data are also available from Hankasalmi, Finland radar $\left(63^{\circ} \mathrm{N}, 27^{\circ} \mathrm{E}\right)$. CUTLASS (Cooperative UK Twin Located Auroral Sounding System) is a pair of HF coherent backscatter radar located in Finland and Iceland and forms part of the SuperDARN array (Greenwald et al., 1995; Milan et al., 1997; Lester et al., 2004). In the course of the experiment CUTLASS operated at three frequencies of about 10, 11.5 and 13.2 MHz. Note that CUTLASS was running a non-standard scan for heating. The Hankasalmi radar had $15 \mathrm{~km}$ range gates, with the first gate starting at a range of $480 \mathrm{~km}$. The beam integration time was $3 \mathrm{~s}$. The scan was restricted to beams from 3 to 7 , and a three-frequency sweep was used.

The status of the ionosphere in the course of the experiment was checked by an ionosonde (dynasonde) at Troms $\varnothing$ (Rietveld et al., 2008). Ionograms were taken every two minutes. The viewing geometry is shown in Fig. 1.

\section{Observational results}

We have analysed HF heater-induced phenomena in the Fregion of the ionosphere. The analysed period was limited to $15: 00$ to $15: 30 \mathrm{UT}$, since after 15:30 UT transmission to the F-region was blocked by absorption/reflection in the Eregion in which very high electron densities were observed. Ionograms obtained on 13 October 2006 during heater-off and heater-on periods are presented in Fig. 2a and b, respectively. Significant spreading in the F2 layer took place throughout the experiment, which is indicative of patchy plasma densities. In the course of the experiment, the iono-

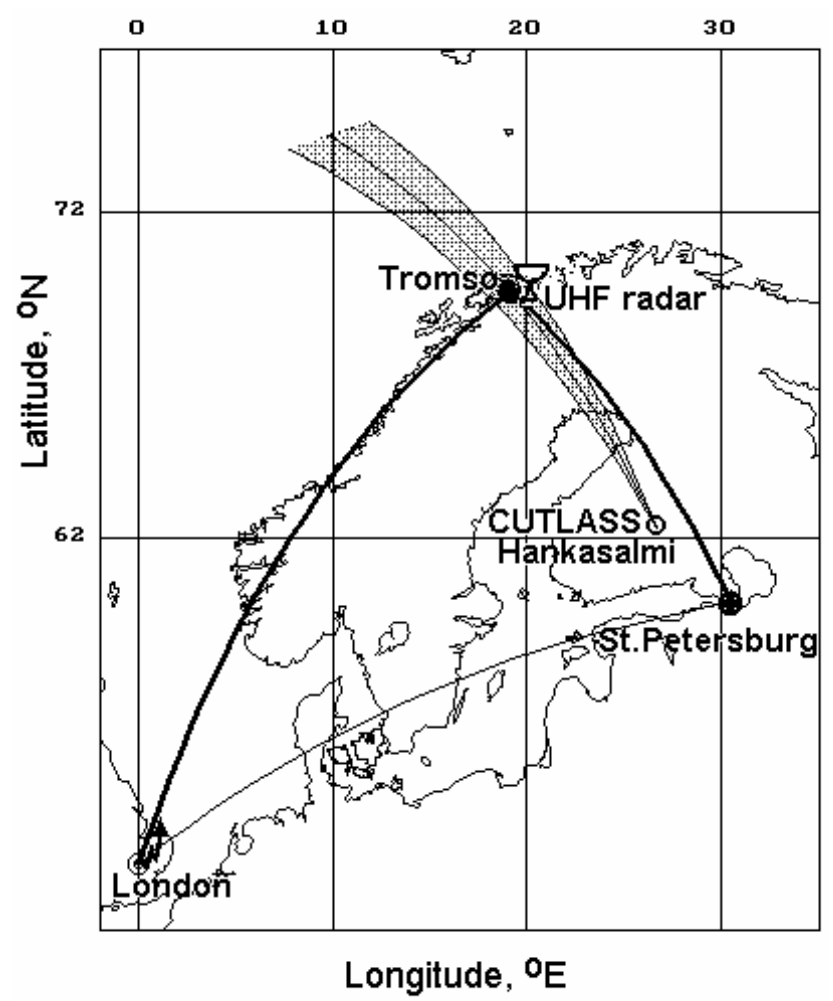

Fig. 1. Map showing the experiment geometry. Bi-static HF Doppler radio scatter observations were carried out on the LondonTroms $\varnothing-$ St. Petersburg paths (thick lines). The London-St. Petersburg direct path is shown on the map by a thin line. The viewing geometry of the Hankasalmi CUTLASS HF coherent scatter radar is also presented on the map.

grams obtained showed that the critical frequencies of the F2 layer $f o \mathrm{~F} 2$ changed from $4.2 \mathrm{MHz}$ at $14: 58 \mathrm{UT}$ to $3.4 \mathrm{MHz}$ at 15:20 UT. The first three ionograms obtained during heateron periods (see Fig. 2b) appear to be weaker, because of an increased HF noise floor when the heater is on, especially near the heater frequency, which happens to be near $f o \mathrm{~F} 2$. For these events, to estimate HF-induced variations in the F-region electron density we used $f x \mathrm{~F} 2$ and calculated the maximum plasma density from that and the electron gyro frequency at the corresponding altitude. In this case the values obtained for fmax $\mathrm{F} 2$ during the heater-on periods were about $4.35,4.25,4.3$, and $3.75 \mathrm{MHz}$ in the first, second, third, and fourth heater-on periods, respectively.

Figure 3 displays dynamic Doppler spectra of HF diagnostic signals on the London-Troms $\varnothing$-St. Petersburg path at an operational frequency of $17640 \mathrm{kHz}$ on 13 October 2006 from 14:59 to 15:16 UT. The vertical white bars on the time axis indicate when EISCAT/HEATING was transmitting. As can be seen from Fig. 3, the signals scattered from AFAIs are observed on the positive part of the Doppler sonogram (marked with white arrows) in four sequential heateron periods from 15:00-15:02, 15:04-15:06, 15:08-15:10, 

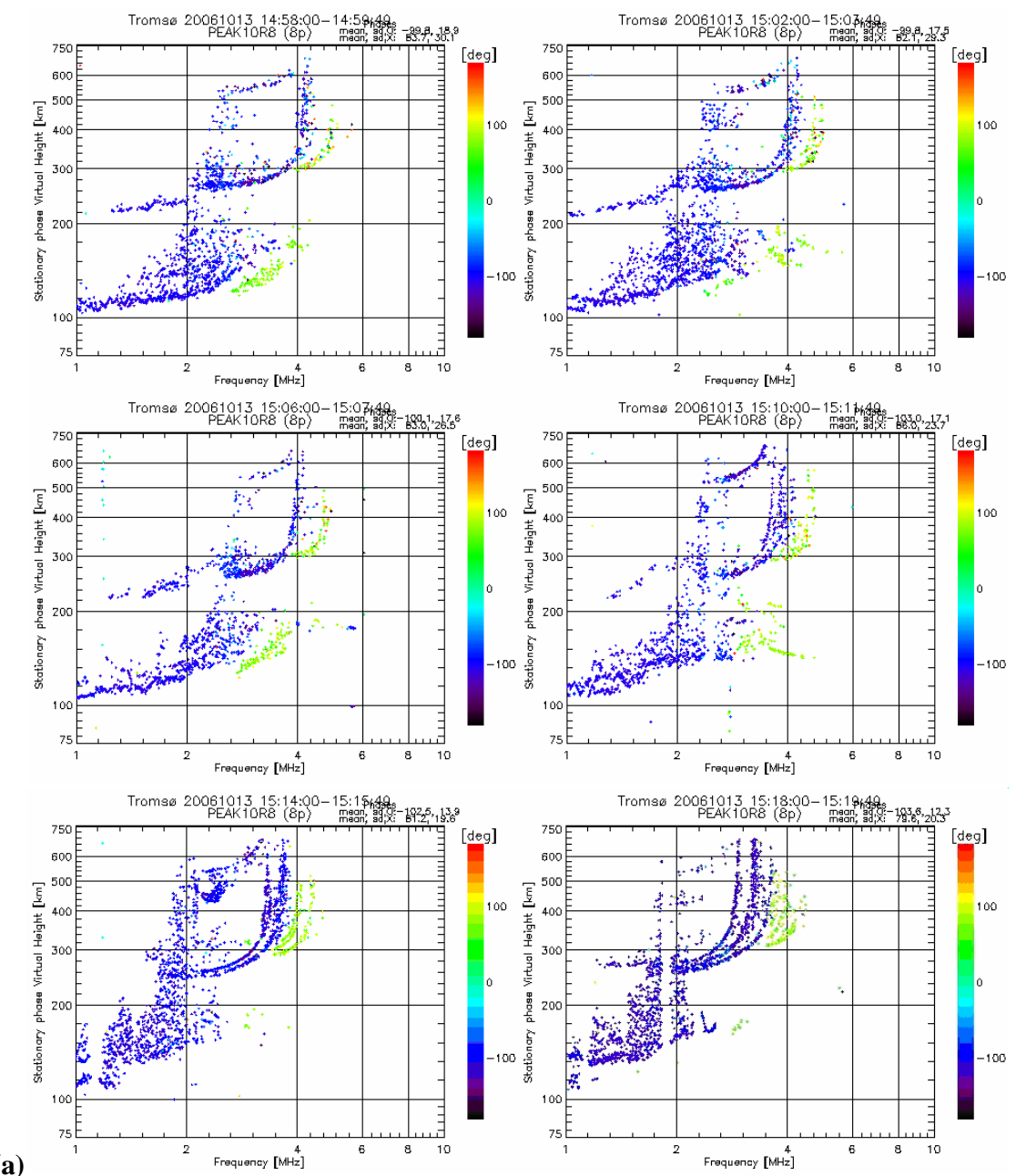

(a)
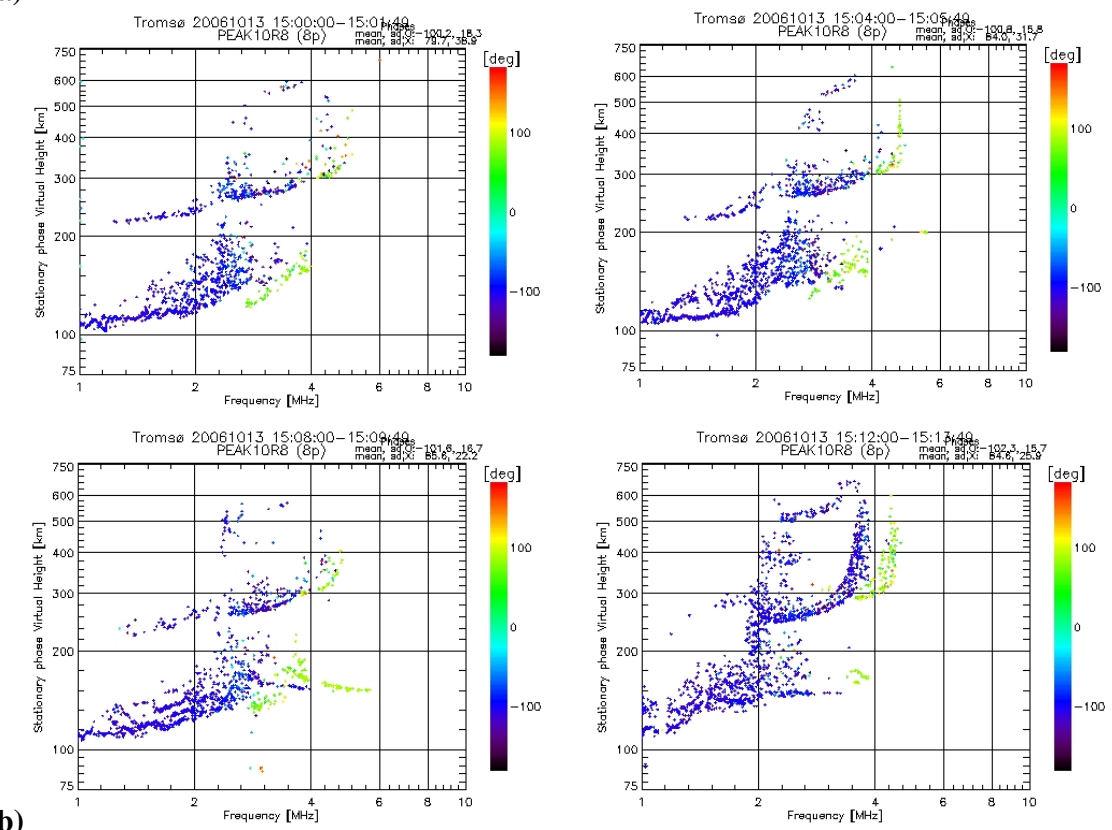

Fig. 2. Ionograms obtained by the dynasonde at Troms $\varnothing$ in the course of the EISCAT/HEATING experiment on 13 October 2006: (a) ionograms taken during heater-off periods; (b) ionograms taken during heater-on periods. 
October 13, 2006, $\mathrm{f}=17640 \mathrm{kHz}$

\section{London -Tromso - St. Petersburg}

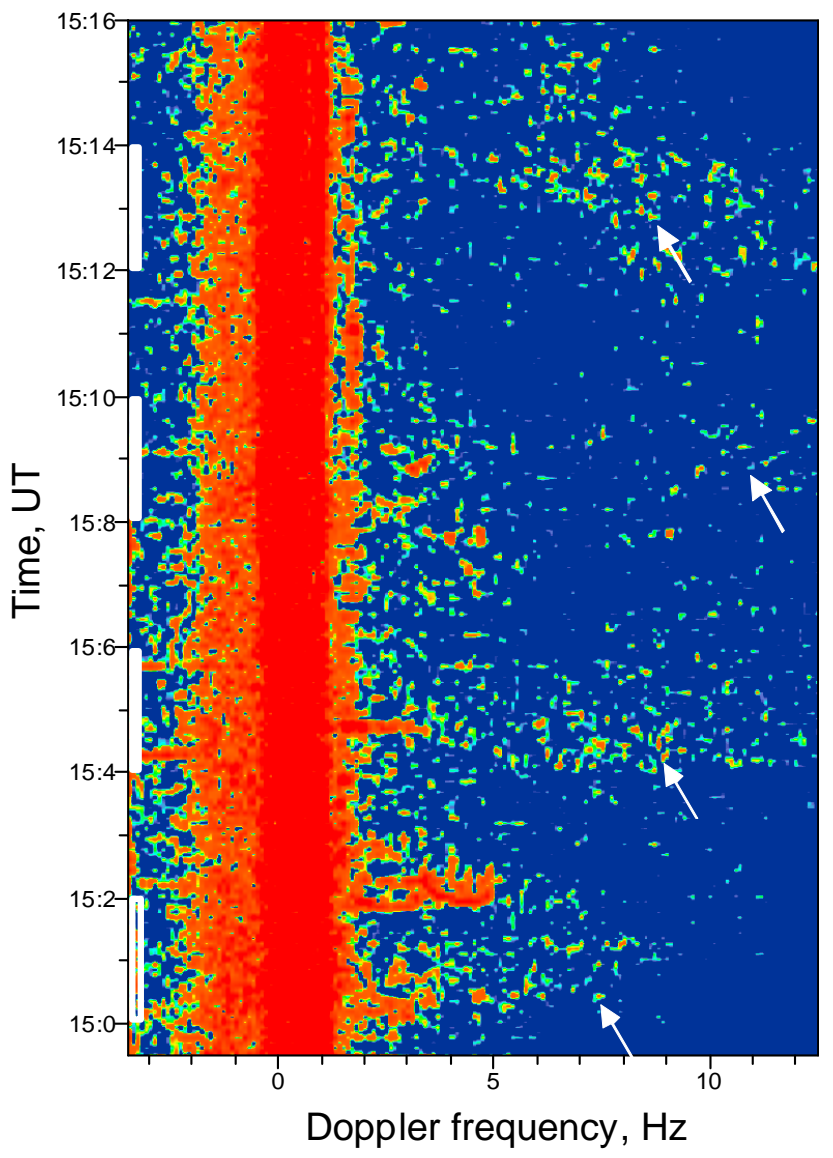

Fig. 3. Dynamic Doppler spectra of HF diagnostic signals on the London-Troms $\varnothing$-St. Petersburg path at an operational frequency of $17640 \mathrm{kHz}$ on 13 October 2006 from 14:59 to 15:16 UT. The vertical white bars on the time axis indicate when the EISCAT/HEATING facility was transmitting. The EISCAT/HEATING facility was operating at $4040 \mathrm{kHz}$ with O-mode polarisation, in cycles of $2 \mathrm{~min}$ on $/ 2 \mathrm{~min}$ off; the heater beam was tilted along the magnetic field-aligned direction (magnetic zenith).

and 15:12-15:14 UT. They exhibit spectral broadening in the band of 7-12 Hz. The spectral power of signals scattered from AFAIs in the positive $\left(S_{+}\right)$part of the Doppler sonogram calculated for 13 October 2006 from 14:59 to 15:16 UT is shown in Fig. 4. The defined increases of the spectral power during the heater-on periods can be seen in Fig. 4.

Data from HF-induced striations detected with CUTLASS Hankasalmi radar on 13 October 2006 between 15:01 and 15:30 UT at operational frequencies of about 10, 11.5, and 13.3 MHz are presented in Fig. 5. CUTLASS data show the increase of the backscatter power at the range of Troms $\varnothing$, observed at the three operational frequencies. The most intense

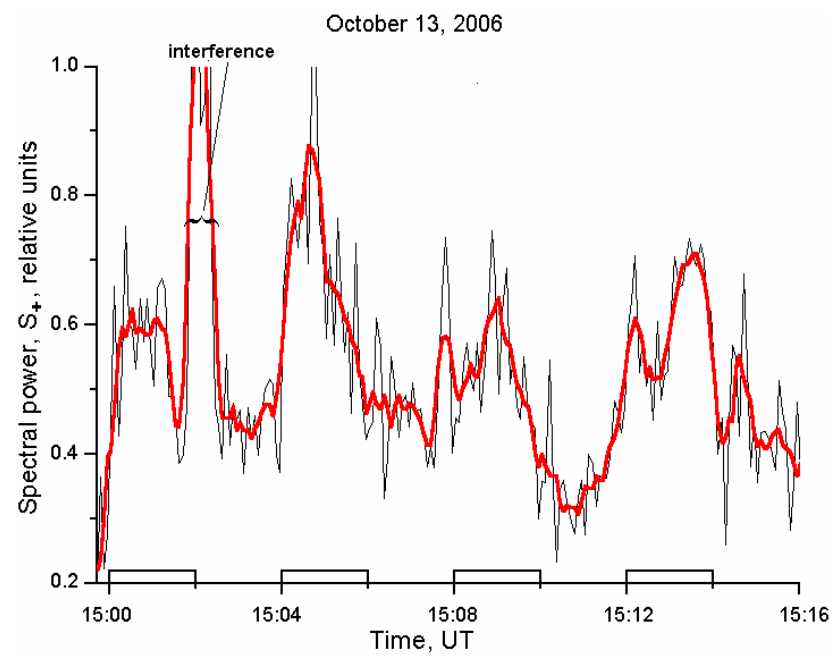

Fig. 4. The spectral power of signals scattered from AFAIs in the positive $\left(S_{+}\right)$part of the Doppler sonogram calculated for 13 October 2006 from $14: 59$ to $15: 16 \mathrm{UT}$.

HF-induced backscatter was observed at $11.5 \mathrm{MHz}$. during the same heater-on periods in which the scattered signals were observed from bi-static HF radio scatter. The heater-on period from 15:08-15:10 UT is the last with backscatter at an operational frequency of $13.2 \mathrm{MHz}$, and 15:12-15:14 UT is the last with backscatter at frequencies of 10 and $11.5 \mathrm{MHz}$.

Comparing the occurrence of striations from Figs. 3 and 5 and Troms $\varnothing$ dynasonde data (Fig. 2a), it can be seen that after the first heater-on period at 15:02 UT, the critical frequency of F2 layer was $f o \mathrm{~F} 2=4.2 \mathrm{MHz}$. After the second one at 15:06 UT, it was $4.1 \mathrm{MHz}$. After the third heater-on period at 15:10 UT it was about $3.9 \mathrm{MHz}$, and after the fourth heater-on period at 15:14 UT it was 3.7 MHz.

Figure 6 presents data from the EISCAT UHF radar data at Troms $\varnothing$ on 13 October 2006 from 14:58 to 15:30 UT as the UHF radar beam pointed in the MZ, showing the effects of HF pumping. One can clearly see the strong electron temperature $T_{e}$ increases (second panel) closely related to the first four heater-on periods in which the heater-induced striations were observed both from bi-static HF Doppler radio scatter and from the CUTLASS radar. In Fig. 6 white horizontal lines near the reflection height of the HF pump wave (most likely at the upper hybrid resonance altitude) in the $N_{e}, T_{e}$, $T_{i}$, and $V_{i}$ panels show data with a high residual to the fitting. The residual is a measure of deviations, the difference between the observed and theoretical curve fits to the radar echo spectra. In such time intervals, closely related to the first three heater-on periods, strongly enhanced ion-acoustic and even central line peaks in the spectra were observed. This is typical of strong Langmuir turbulence. The altitude of this heater-induced Langmuir turbulence was about $230 \mathrm{~km}$, and did not change during the experiment. It is important to note that at the altitude of $230 \mathrm{~km}$ the pump frequency is just 


\section{SUPERDARN PARAMETER PLOT 13 Oct $2006^{2086}$}

Hankasalmi: pwr_I

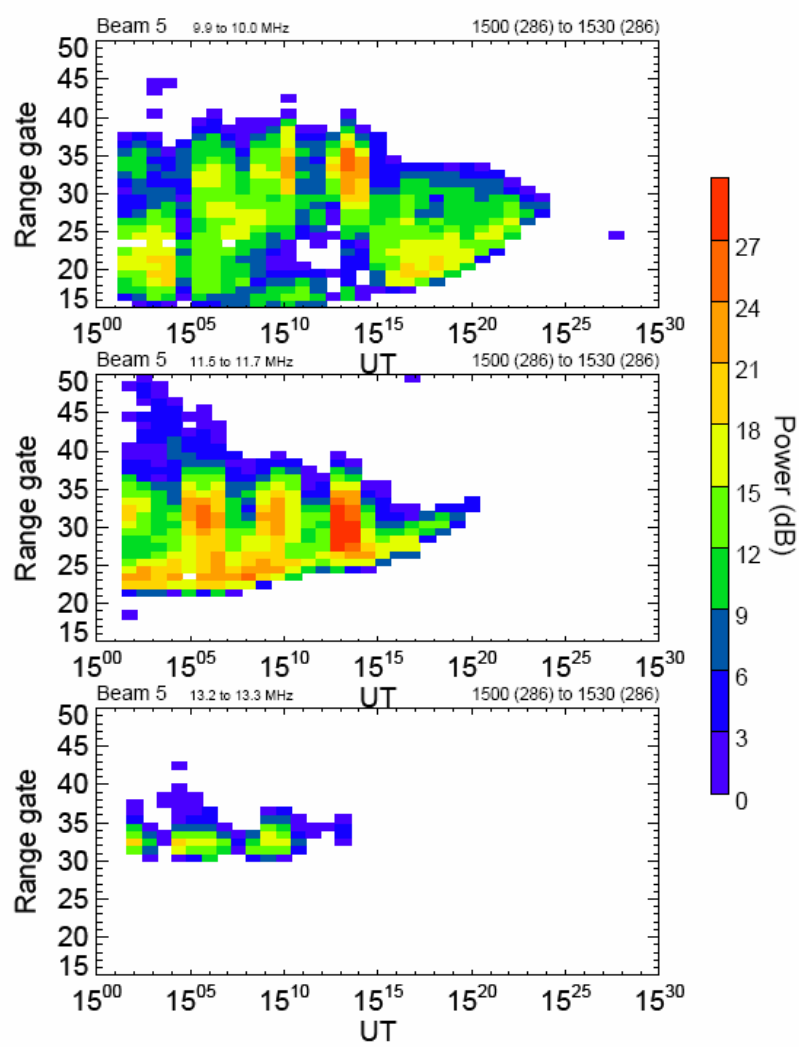

Fig. 5. Backscattered power from the Hankasalmi (Finland) CUTLASS radar at operational frequencies of about 10, 11.5 and 13.3 MHz on 13 October 2006 between 15:01 and 15:30 UT. The CUTLASS Hankasalmi radar was running a non-standard scan for heating. It had $15 \mathrm{~km}$ range gates, with the first gate starting at a range of $480 \mathrm{~km}$. The EISCAT/HEATING facility transmitted from 15:00-15:02, 15:04-15:06, 15:08-15:10, and 15:12-15:14 UT.

below the third electron gyro harmonic. Although the single altitude range-gate ( $230 \mathrm{~km}$ altitude), in which the HF-driven instability leads to a strong ion-line enhancement, is difficult to analyze for temperatures and densities, adjacent altitudes can be used to examine plasma responses.

Temporal variations of the electron density $N_{e}$, ion and electron temperatures, $T_{i}$ and $T_{e}$, and ion velocities $V_{i}$ at altitudes of 214, and $264 \mathrm{~km}$ from the EISCAT UHF radar observations on 13 October 2006 from 14:58 to 15:15 UT are shown in Fig. 7a and b, respectively. Figure 8 shows the temporal variations of EISCAT UHF radar residuals at the three altitudes of 230, 214, and $264 \mathrm{~km}$. Note that the data with a residual of more than 2 cannot be trusted. From Fig. 8 residuals at altitudes of 214 and $264 \mathrm{~km}$ stayed mainly below the threshold value of 2 . At $230 \mathrm{~km}$ the residuals were more than 2.0 in parts of the first three heater-on periods. In Fig. 7a, b note particularly the following features: Increases in electron temperature $T_{e}$ were observed at the two altitudes in the first four heater-on periods from 15:00-15:02, 15:0415:06, 15:08-15:10, 15:12-15:14 UT. During the first three heater-on periods, when HF pumping was produced near the critical frequency $f_{o} \mathrm{~F} 2, T_{e}$ increases were accompanied by real electron density enhancements up to $25 \%$, at the altitudes immediately above and below $230 \mathrm{~km}$. At $214 \mathrm{~km}$ the defined $N_{e}$ increases occurred in the first and second heateron periods, and at $264 \mathrm{~km}$ they were observed in the first and third heater-on periods.

We note with respect to the electron temperature $T_{e}$, measured by the UHF radar, that the last clearly enhanced $T_{e}$ was measured during the HF-on period from 15:12-15:14 UT, but contrary to the first three heater-on periods this $T_{e}$ enhancement was not accompanied by an increase in the $N_{e}$. The first HF-on cycle during and after which no detectable $T_{e}$ enhancement was seen was from 15:16-15:18 UT.

Figure 9 presents the temporal variations of electron density from both the maximum of the F2 layer and from $214 \mathrm{~km}$, as estimated from the $N_{e}(h)$ profiles obtained from the Troms $\varnothing$ dynasonde data (see Fig. 2a, b). Recall that during heater-on periods we used $f x \mathrm{~F} 2$ and calculated the maximum plasma density from it and the electron gyro frequency at the corresponding altitude. From Fig. 9 we note that some enhancements in the electron density were also observed from dynasonde data in the first three heater-on periods. As a whole, values of electron densities are less than or comparable to UHF radar measurements in the MZ.

Figure 10a-d presents electron density profiles $N_{e}(h)$ from heater-on (red line) and preceding heater-off (blue line) periods obtained from UHF radar measurements for the first, second, third, and fourth heating cycles respectively. The clearest heater-induced effects in the plasma density are seen in the first three heater-on periods in a wide altitude range of up to $100 \mathrm{~km}$.

\section{Discussion}

We have considered multi-instrument observational data from an experiment on 13 October 2006 at the EISCAT/HEATING facility at Troms $\varnothing$, Norway, when the electron density in the F-region dropped and the heater frequency was near and then above the critical frequency of the F2 layer. In the course of the experiment the pump frequency was very close to and just below the third electron gyro harmonic frequency. The instruments used to diagnose the HF pumpinduced phenomena were the bi-static HF radio scatter on the London-Troms $\varnothing$-St. Petersburg path, the CUTLASS radar in Hankasalmi (Finland), the European Incoherent Scatter (EISCAT) UHF radar at Troms $\varnothing$, and the Troms $\varnothing$ dynasonde. During the experiment both the HF pump beam and the UHF radar beam were directed towards the magnetic zenith (MZ). The HF pump wave clearly matched the upper hybrid resonance layer in which striations are generated. The results 


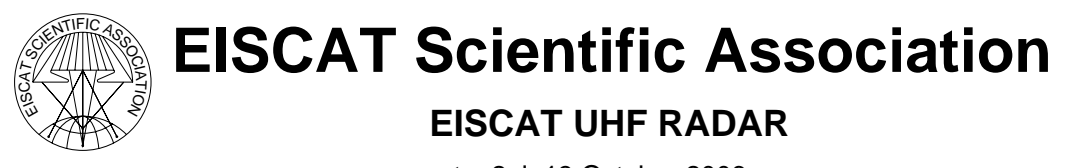

tau2pl, 13 October 2006
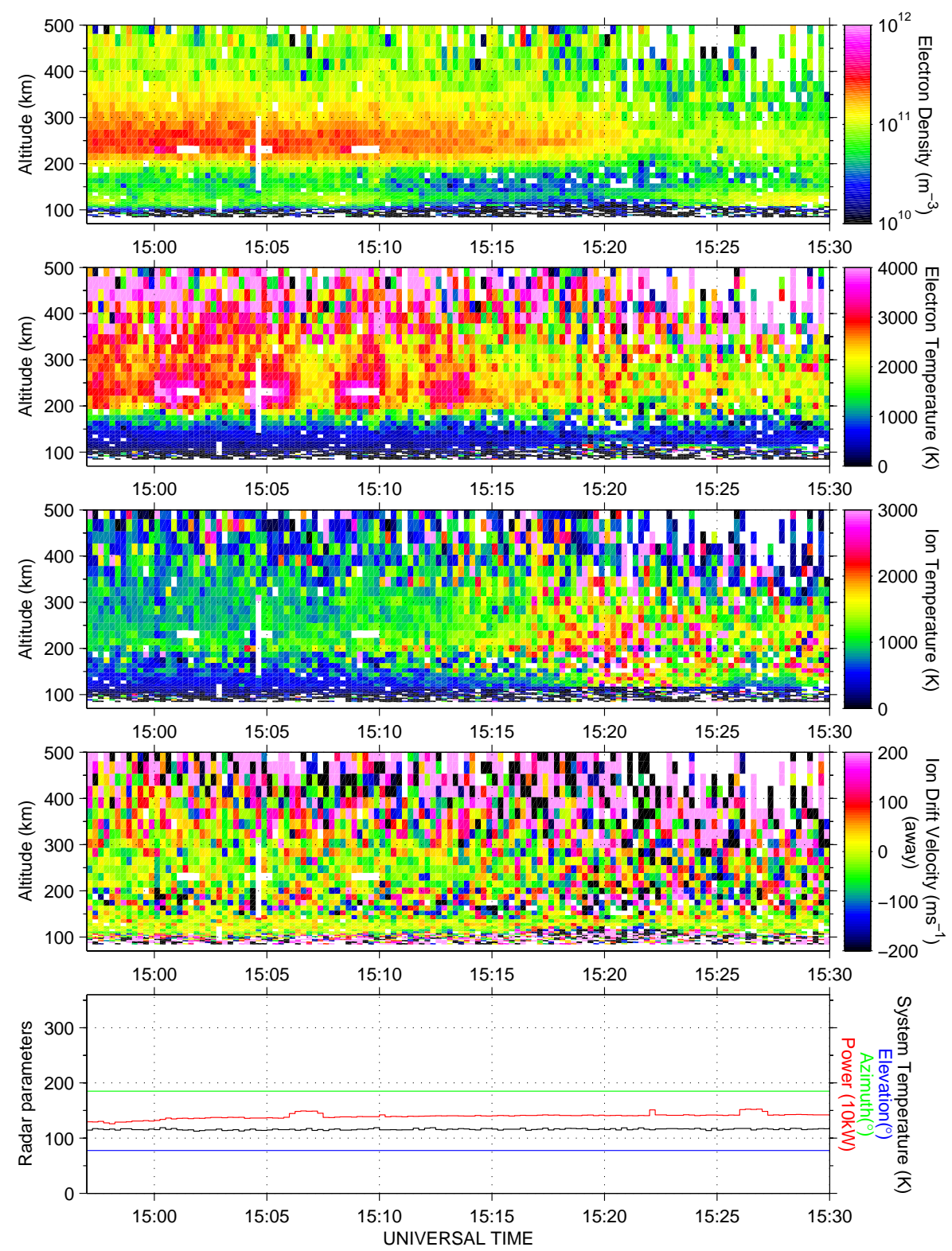

Fig. 6. Data from the EISCAT UHF radar at Tromsø, showing the effects of HF pumping on 13 October 2006 from 14:58 to 15:30 UT. The UHF radar beam pointed towards magnetic zenith, collecting long-pulse mode data analyzed with $15 \mathrm{~s}$ integration time. The EISCAT/HEATING facility was operated from 15:00 to 19:00 UT with a 2 min on, 2 min off pump cycle. White horizontal lines at the single range gate about $230 \mathrm{~km}$ near the reflection height of the HF pump wave (the range gate most likely also including the upper hybrid resonance altitude) in the $N_{e}, T_{e}, T_{i}$, and $V_{i}$ panels, and closely related to the first three heater-on periods, show data with a high residual to the fitting. This high residual error-bar is typical of echoes with strong Langmuir turbulence.

obtained have shown the excitation of the HF-induced striations seen simultaneously from HF bi-static scatter and CUTLASS radar observations, and strong HF-induced electron heating in the first four heater-on periods when the heater frequency $f_{H}$ was near and above the critical frequency of F2 layer. Furthermore, increases in the electron density were 


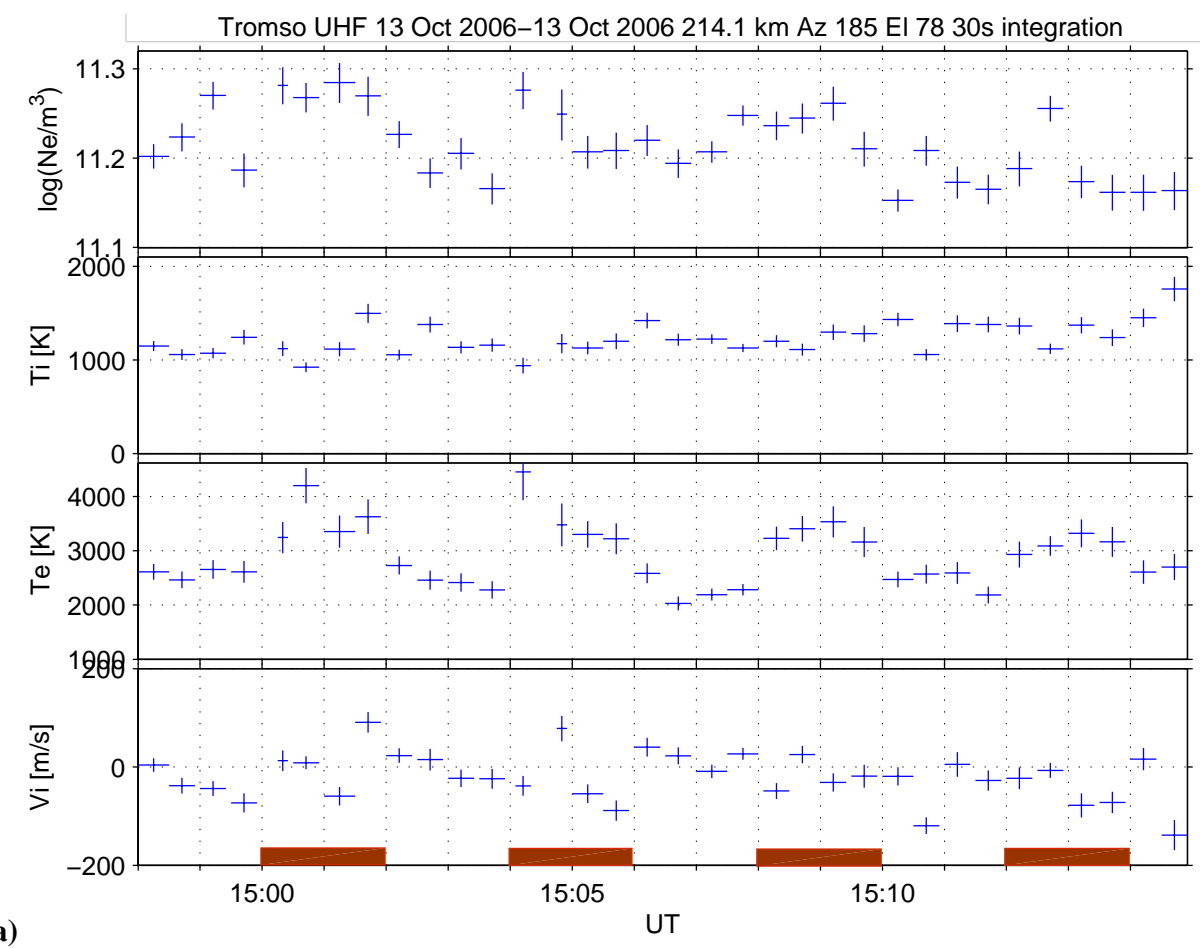

(a)

Tromso UHF 13 Oct 2006-13 Oct 2006264.4 km Az 185 El 78 30s integration

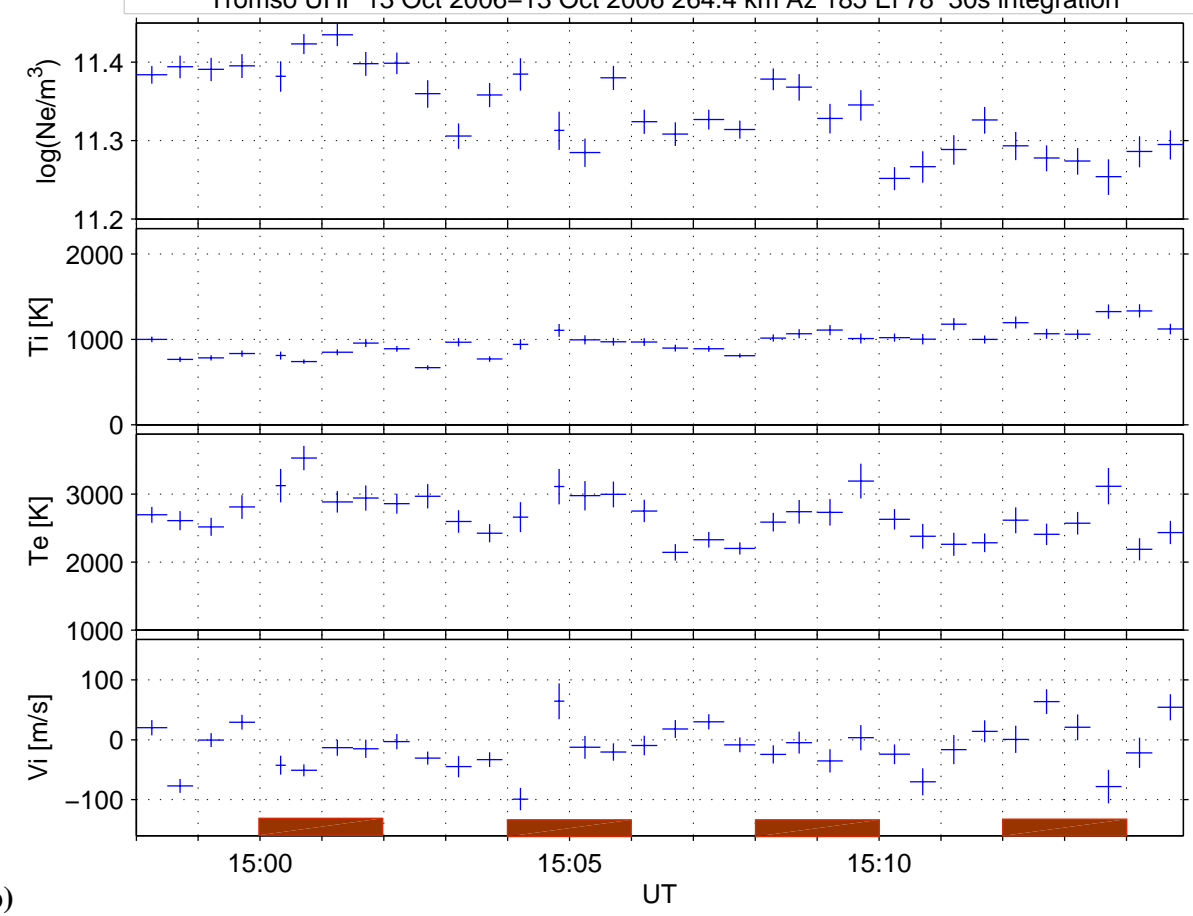

Fig. 7. Temporal variations of the electron density, $N_{e}$, ion and electron temperatures, $T_{i}$ and $T_{e}$, and the ion velocity, $V_{i}$, from the EISCAT UHF radar observations on 13 October 2006 from 14:58 to 15:15 UT at different altitudes: (a) $214 \mathrm{~km}$; (b) $264 \mathrm{~km}$.

observed in a wide altitude range up to $100 \mathrm{~km}$, during only the first three heater-on periods. At the altitudes of 214 and $264 \mathrm{~km}$, which are respectively below and above the upper hybrid resonance altitude of $230 \mathrm{~km}$, the EISCAT UHF radar measured enhancements of the electron density by up to $25 \%$. Troms $\varnothing$ dynasonde data also show some increases in $f o \mathrm{~F} 2$ in the first three heater-on periods. 


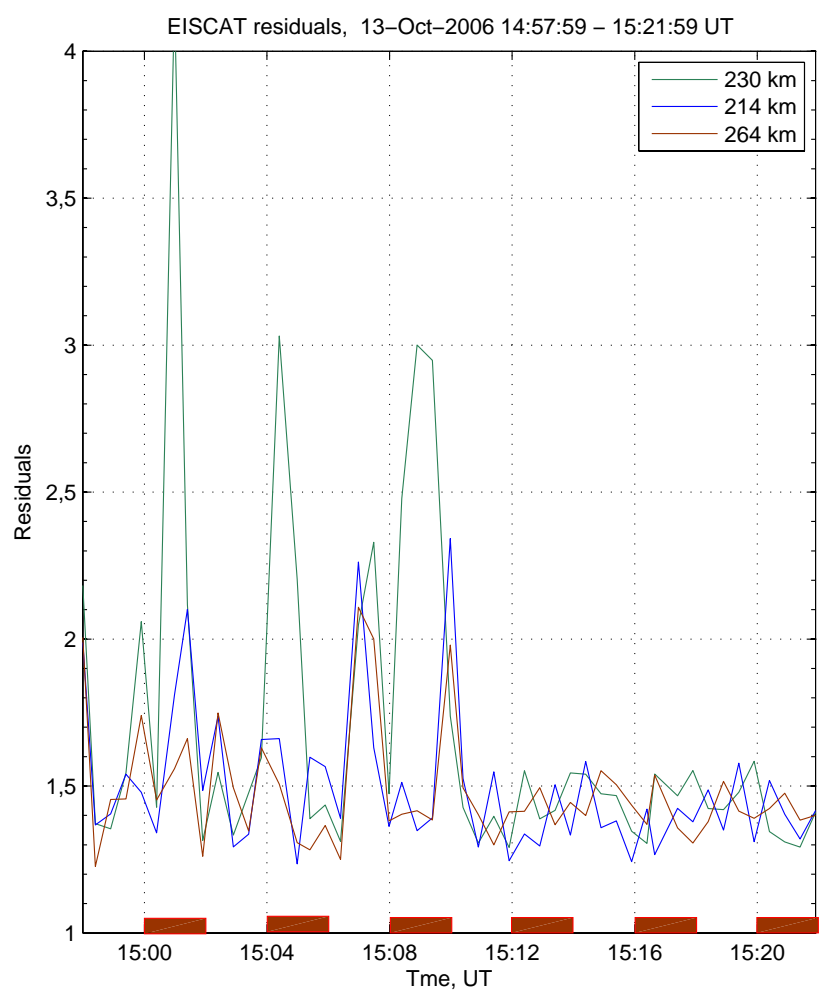

Fig. 8. Temporal variations of residuals of EISCAT UHF radar data at altitudes of 214,230 , and $264 \mathrm{~km}$.

Electron heating by the upper hybrid resonance, creating AFAIs, always leads to decreased electron density in the striations. This decreased density in turn further focuses HF radio waves into plasma density depletions. Hence the AFAIs grow nonlinearly, forming bunches of striations (Gurevich et al., 1998). If the pump HF radio waves propagate sufficiently close to parallel to Earth's magnetic field $\boldsymbol{B}$, the waves can be trapped, thereby depositing most of the HF energy in the plasma (Gurevich et al., 2001). Observations which confirm this prediction were made simultaneously at EISCAT/HEATING facility at Troms $\varnothing$ (Leyser et al., 2000; Kosch et al., 2002; Rietveld et al., 2003) and HAARP (Pedersen and Carlson, 2001; Gurevich et al., 2002; Pedersen et al., 2003). This strong enhancement of trapped HF waves near parallel to $\boldsymbol{B}$, leading to the magnetic zenith effect, has since been studied at these and other HF facilities. Several such studies have focused on optical emissions. It was shown that HF-induced airglow maximizes during HF pumping towards magnetic zenith (Kosch et al., 2002; Pedersen et al., 2003). The same is true for some Langmuir turbulence phenomena, which also show a strong preference for excitation by pump $\mathrm{HF}$ radio waves in the field-aligned direction (Isham et al., 1999). The generation of strong Langmuir turbulence with upper hybrid waves as the primary source of Langmuir waves has been proposed by Mishin et al. (2004), who has shown an extended strong-turbulence region. Rietveld et al. (2003)

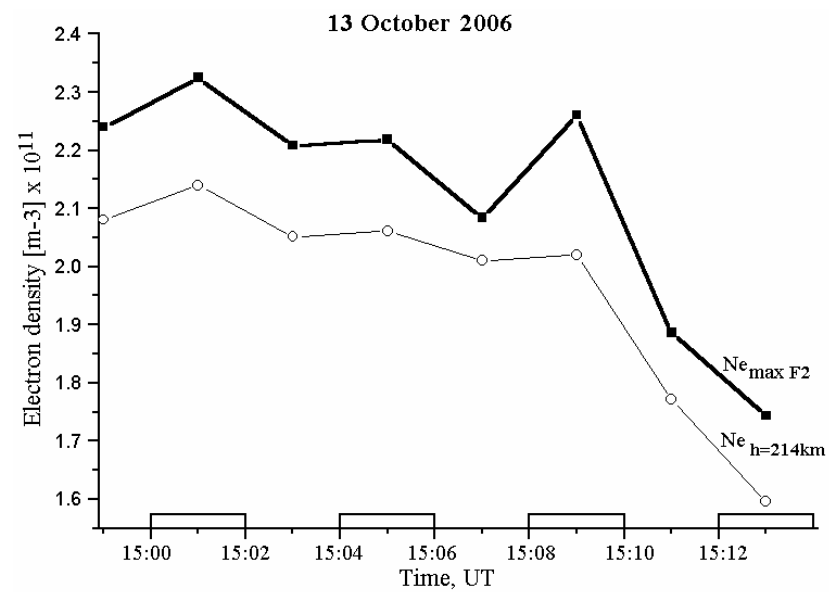

Fig. 9. Temporal variations of electron density from the maximum of the F2 layer, and from $214 \mathrm{~km}$ estimated from $N_{e}(h)$ profiles obtained from Troms $\varnothing$ dynasonde data on 13 October 2006 from 14:58 to $15: 14$ UT.

have shown that in the course of EISCAT/HEATING experiments, where both the HF pump beam and the UHF radar beam were scanned in elevation between magnetic zenith and vertical directions, the heating effects, such as large electron temperature increases, intense AFAIs, and HF-induced optical emission, all maximized during HF pumping towards MZ. They also showed that large electron temperature increases of $3000 \mathrm{~K}$ above the background were accompanied by ion heating of about $100 \mathrm{~K}$, and electron density decreases of up to $20 \%$. Here we add insights for the HF pump-induced phenomena when the HF heater frequency on the one hand was very close to the third electron gyro harmonic frequency, and on the other hand was near the critical frequency of the F2 layer.

We observe plasma density increases by up to $25 \%$. Such plasma density increases might result from three mechanisms which we examine below: (1) Changed temperaturedependent reaction rates, leading to transiently changed plasma density (Sipler and Bionde, 1972). (2) Redistribution of thermal plasma due to changed electron gas temperature and diffusion rates (Meltz and LeLevier, 1970). (3) Enhanced production of ionization by accelerated electrons (Carlson, 1993).

(1) Temperature-dependent reaction rates: Sipler and Biondi (1972) measured a transient decrease in $630.0 \mathrm{~nm}$ emission at Arecibo, due to an HF heater-induced increase in electron temperature, and explained this as a consequence of transient reduction in dissociative recombination. They give the formulas used to do a theoretical calculation, which fit the data well, for an estimated $1.3 \%$ intensity suppression of $630.0 \mathrm{~nm}$ intensity, due to reduced ion-electron recombination, with a time constant of $21 \mathrm{~s}$, corresponding to an $11 \%$ increase in electron temperature. This change in plasma density is only transient, as the sudden increase in 

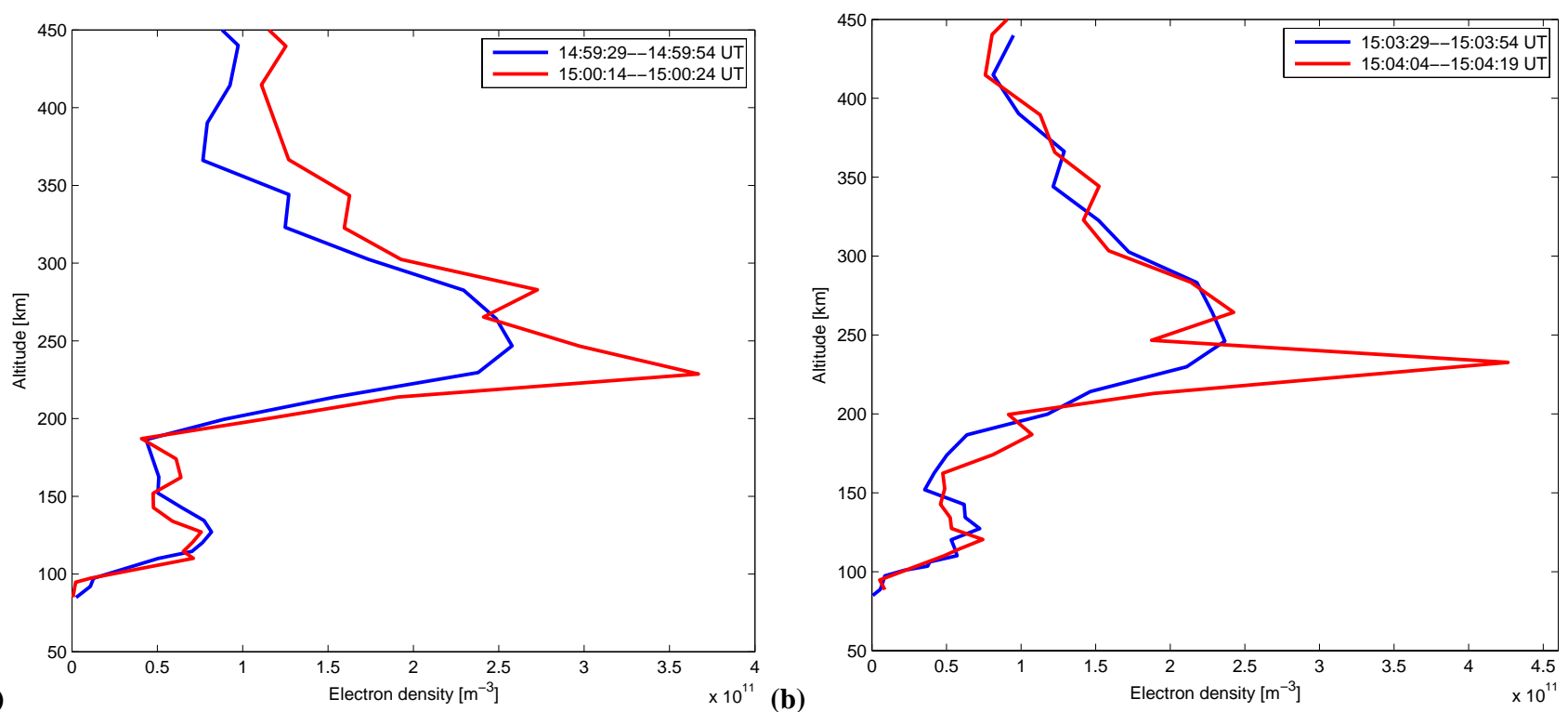

(a)

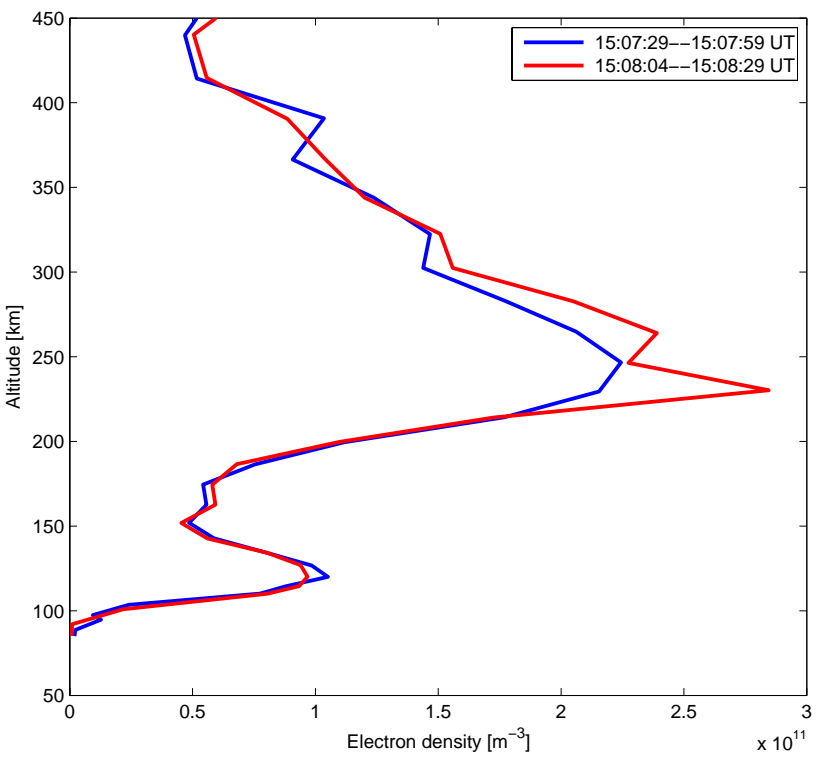

(b)

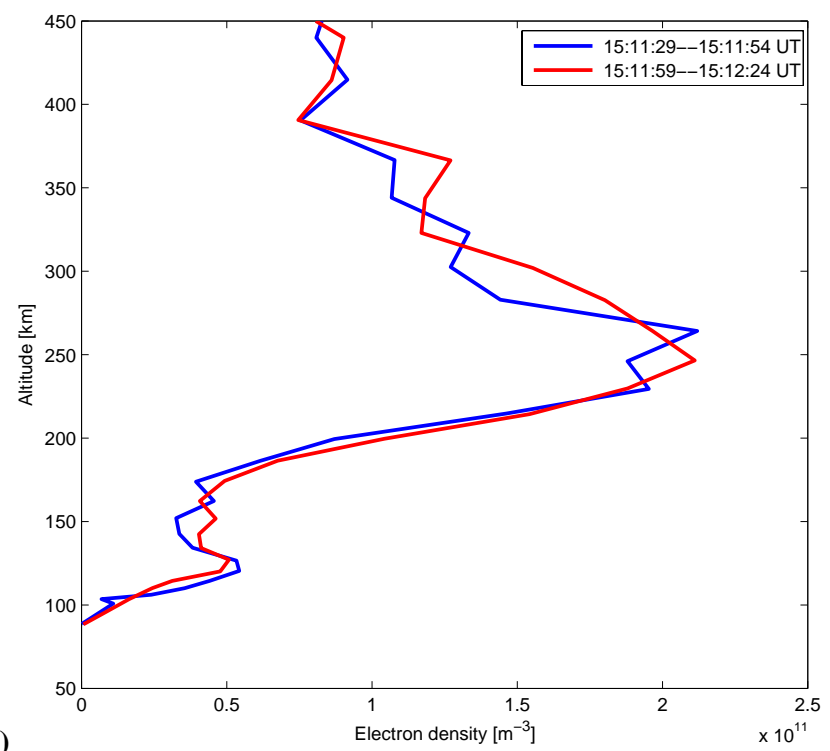

Fig. 10. Electron density profiles $N_{e}(h)$ from heater-on (red line) and preceding heater-off (blue line) periods obtained from UHF radar measurements on 13 October 2006: (a) the first HF-cycle; (b) the second HF-cycle; (c) the third HF-cycle; (d) the fourth HF-cycle.

the electron temperature. It leads to a momentary decrease in $\mathrm{O}\left({ }^{1} \mathrm{D}\right)$ concentration, $630.0 \mathrm{~nm}$ emission, dissociative recombination, and thus to a transient increase of plasma density, after which the rate-limiting charge transfer from atomic oxygen ions restores the initial steady-state plasma density. We must test whether this process can explain the transient plasma density increase here. The formula for the temperature dependence and the coefficient for the density suppression, which they used for that calculation and which fit the data, has since been updated as per Schunk and Nagy (2000) for temperatures above $1200 \mathrm{~K}$, yet gives essentially the same numerical values. Here we must replace the Sipler and
Biondi (1972) oxygen-ion-only calculation by total ion density, and calculate plasma density changes for our conditions, where the electron temperature changes will be significantly greater than the 1972 Arecibo data and thus temperaturedependent change will likewise be greater than the $1.3 \%$ seen at Arecibo. The following equation was used to model the electron density response to increases in the electron temperature $T_{e}$ (Schunk and Nagy, 2000):

$$
\frac{d n_{e}}{d t}=q(h, t)-\frac{\left(k 1\left[\mathrm{~N}_{2}\right]+k 2\left[\mathrm{O}_{2}\right]\right)}{1+\frac{k 1\left[\mathrm{~N}_{2}\right]}{a 1 \times n_{e}}+\frac{k 2\left[\mathrm{O}_{2}\right]}{a 2 \times n_{e}}} \times n_{e},
$$


where $q$ with a steady-state assumption was estimated for the time just before the heater-on. Here the rate coefficients are:

$k 1=1.2 \times 10^{-12}$,

$k 2=2.1 \times 10^{-11} \times\left(1200 / T_{e}\right)^{0.4}$,

$a 1=2.2 \times 10^{-7} \times\left(1200 / T_{e}\right)^{0.39}$,

$a 2=7.38 \times 10^{-8} \times\left(1200 / T_{e}\right)^{0.56}$.

The calculations of electron density response to increases in $T_{e}$ were performed for three altitudes of 214,230 , and $264 \mathrm{~km}$ with a time constant of $30 \mathrm{~s}$, when increases in electron temperatures due to $\mathrm{HF}$ pumping effects varied from 50 to $100 \%$. The [N2] and [O] densities for corresponding altitude were taken from the MSIS model (http: //omniweb.gsfc.nasa.gov/vitmo/msis_vitmo.html). The calculations give electron density increases from 2.4 to $5.3 \%$, depending on the altitude and $T_{e}$ enhancements. These calculations ignoring transport (discussed below) give an upper limit to the impact of this process.

A more straightforward proof derives from the direct comparison with observations on the preceding day, 12 October. We compared results obtained on 13 October 2006 with data collected during our experiment on 12 October 2006, which bears a close resemblance to the one discussed here. It was conducted in the same time-of-day, HF pumping was also produced towards MZ, the same heater frequency and modulation were used, and the UHF radar was in operation. We have examined the plasma density and electron temperature on both days. Figure 11a, b shows data from two range gates, both of which are free of any HF ion-line enhancement. The Fig. 11a, b data from the EISCAT UHF radar observations on 12 October 2006 from 15:28 to 15:52 UT, when the F2 layer critical frequency fell through $f_{H}$ on this day, presents temporal variations of the electron density $N_{e}$, ion and electron temperatures $T_{i}$ and $T_{e}$, and ion velocities $V_{i}$, at altitudes of 214 and $264 \mathrm{~km}$. We look first at the changes in the electron density on 12 October (Fig. 11b), and find no convincing evidence of any increase at $264 \mathrm{~km}$. The next day, 13 October (see Fig. 7b) showed an increase in electron density in the first and third heater-on periods. In fact the $T_{e}$ increase for 13 October (see Fig. 7b) was less, being heated from roughly 2300 to $3500 \mathrm{~K}(\sim 50 \%)$, vs. from roughly 1800 to $3200 \mathrm{~K}$ $(80 \%)$ on 12 October (see Fig. 11b). No detectable changes in ion temperatures were observed near these altitudes on either day. (Note: The higher unheated base electron temperature on 13 October was consistent with the slightly lower plasma density. On 12 October the background electron density was larger, $f o \mathrm{~F} 2$ from dynasonde data at Troms $\varnothing$ was about $4.4 \mathrm{MHz}$ ). By this electron temperature-dependent effect alone, if the 13 October plasma density increase was due to electron gas temperature changes, 12 October would show even greater plasma density increases. In fact no noticeable increase in plasma density was seen. The behavior of electron density at the altitude of $214 \mathrm{~km}$ (Figs. $7 \mathrm{a}$ and 11a) is similar to those observed at the altitude of $264 \mathrm{~km}$. Thus we cannot explain the 13 October plasma density increase by this effect, consistent with the detailed calculations.

Thus we conclude from both the data alone and from the model calculations, that the $N_{e}$ enhancement on 13 October 2006 by $25 \%$ cannot be explained by temperature-dependent reaction rates.

(2) Redistribution of thermal plasma: Meltz and LeLevier (1970) did the first estimate of how long it would take for this diffusion-constrained redistribution to measurably change plasma densities during HF heating experiments. Plasma transport by hydrodynamic expansion of heated plasma along magnetic field lines is a well established fact. Here after turn-on in heating experiments, the response time to the temperature-dependent pressure gradient is limited by ion drag that is, ions diffusing through neutral particles. Plasma density would decrease slightly at the peak density and increase above and below the peak. The response time, from 5 to $10 \mathrm{~min}$ or more, is found to be much too sluggish to explain our observations for this $2 \mathrm{~min}$ on $/ 2 \mathrm{~min}$ off cycle. Because of this the only argument remains for an increase in plasma density.

(3) Enhanced production of ionization: Carlson (1993) predicted measurable increases in plasma density to be feasible, due to enhanced production of ionization by accelerated electrons, once HF heating facilities reached the GW class of effective radiated power (ERP) densities. This quantitative prediction was based on calculations for achieving HF energy densities approaching that of solar EUV in the F-region, and finding means to efficiently convert the HF energy to the suprathermal electron energy through electron acceleration processes.

The key arguments from that work (Carlson, 1993) are as follows: (1) The electron production rate by the sun for a sunspot number of 60 is $10^{3} \mathrm{~cm}^{-3} \mathrm{~s}^{-1}$, spread in altitude over order $100 \mathrm{~km}$, representing $\sim 4 \times 10^{-8} \mathrm{~W} \mathrm{~cm}^{-2}$. (2) $\mathrm{A}$ GW ERP HF facility would deliver about of $\sim 10^{-7} \mathrm{~W} \mathrm{~cm}^{-2}$ near the F-region peak altitude. (3) The efficiency of conversion of HF energy to the electron energy accelerated above the ionization threshold for effective ionization production (taking $\sim 30 \mathrm{eV}$ per ionization) was established by Carlson et al. (1982) to be order $10 \%$ at order 100 MW ERP. (4) With judicious selection of future operating modes, comparable efficiencies should be realizable, and appreciable production of ionization should be seen. We find the observations here support both that frame of reference and that prediction.

That the presence of suprathermal electrons is a standard feature of HF heating experiments at all latitudes is well established experimentally. HF-excited airglow enhancements were first reported at $630.0 \mathrm{~nm}$ (Sipler and Biondi, 1972) where they are most easily seen, but they can be and are found in HF experiments, due to both thermal and accelerated electrons (Carlson, 2002). More sophisticated optical experiments have since unambiguously established optical emissions excited at wavelengths that can only be excited by 


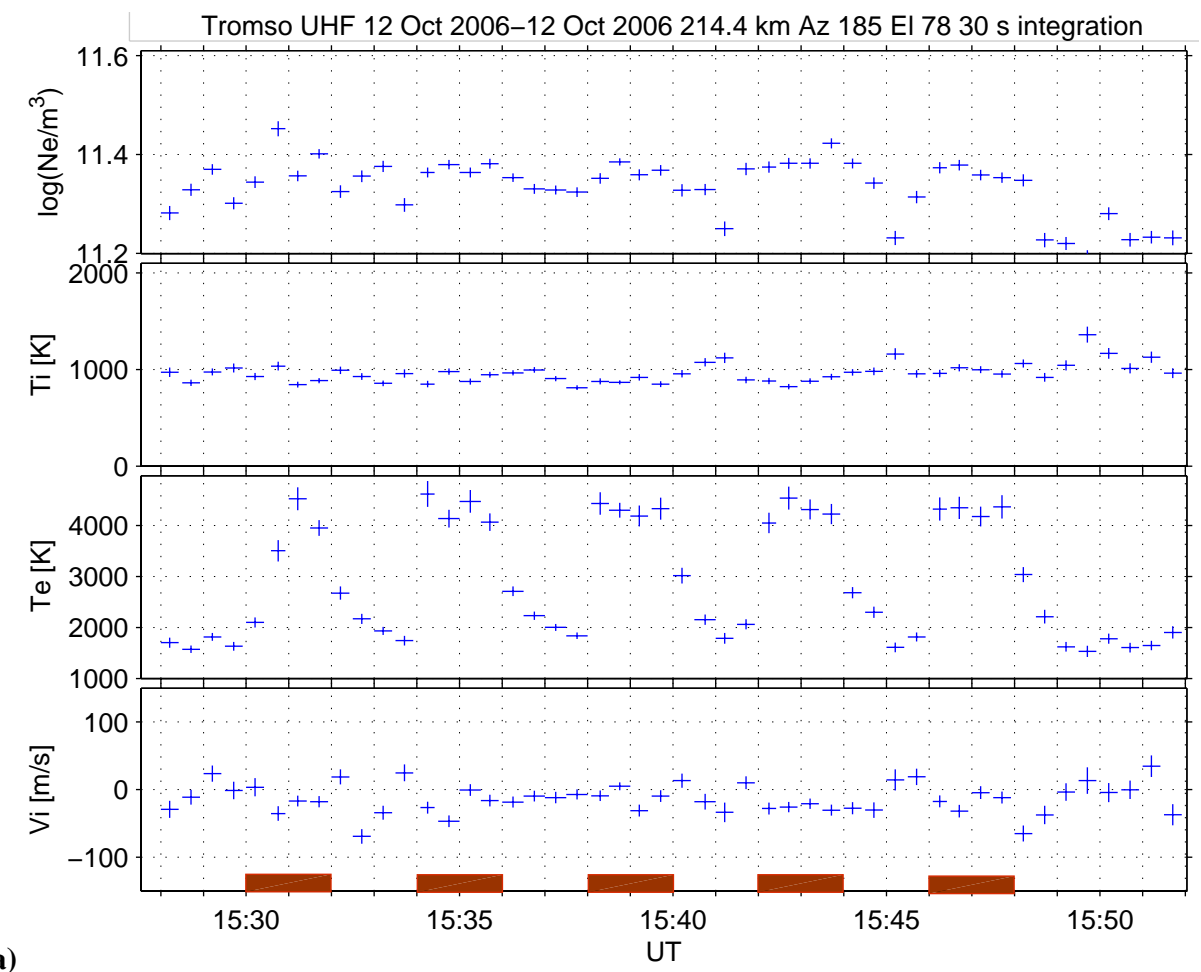

(a)

Tromso UHF 12 Oct 2006-12 Oct $2006264.5 \mathrm{~km} \mathrm{Az} 185$ El 7830 s integration

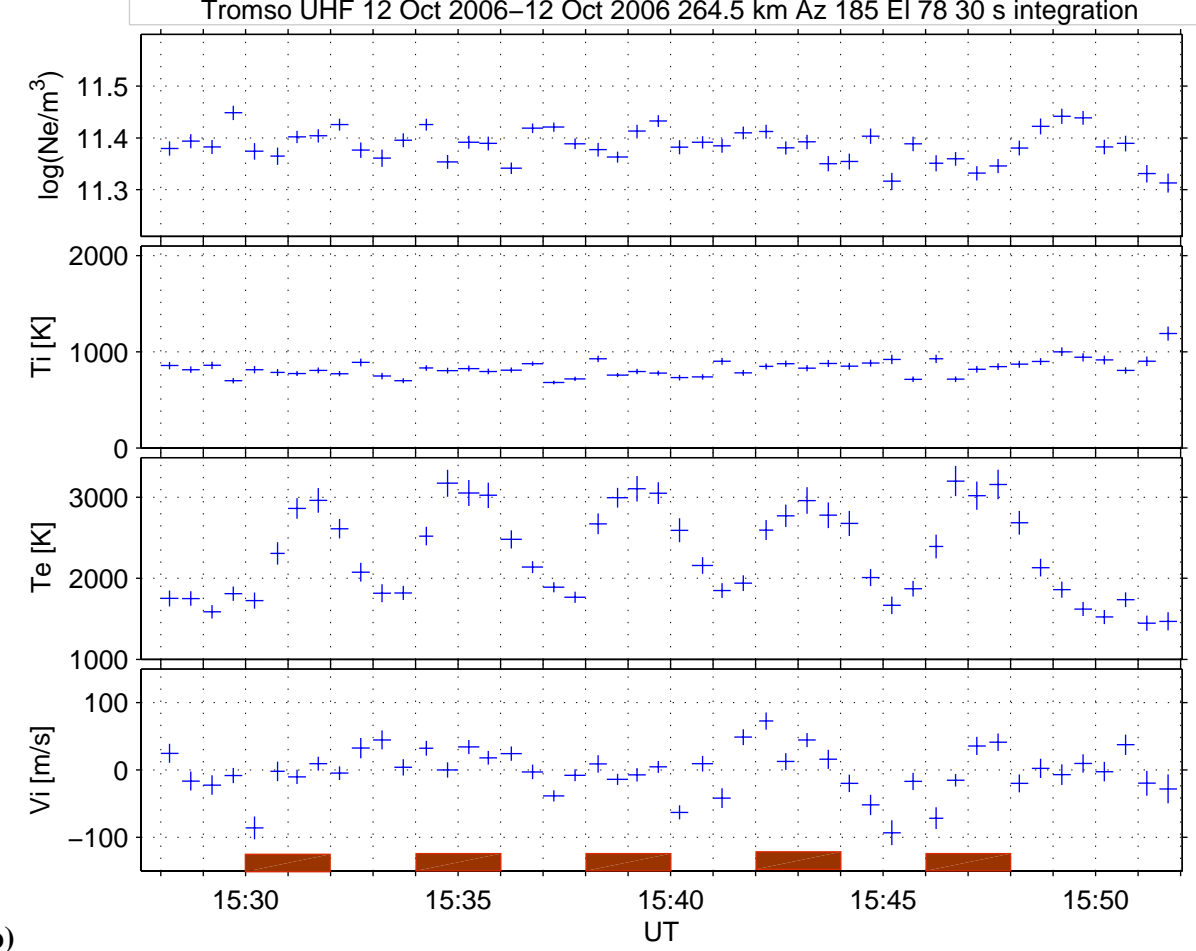

Fig. 11. Temporal variations of the electron density, $N_{e}$, ion and electron temperatures, $T_{i}$ and $T_{e}$, and the ion velocity, $V_{i}$, from the EISCAT UHF radar observations on 12 October 2006 from 15:28 to 15:52 UT at different altitudes: (a) $214 \mathrm{~km}$; (b) $264 \mathrm{~km}$.

suprathermal electrons. These suprathermal electrons produce enhanced optical emissions at 557.7 (Bernhardt et al., 1989; Pedersen et al., 2003), 777.4 (Carlson, 2002; Djuth et al., 2005), 844.6 (Gustavsson et al., 2005), 427.8 (Holma et al., 2006), 660.0 (Djuth et al., 1999) which can complement thermal excitation of $630.0 \mathrm{~nm}$ optical emissions (Carlson, 
2002), and are also seen directly in enhanced incoherent scatter radar plasma lines (Carlson et al., 1982).

The theory underlying the magnetic zenith effect (Gurevich et al., 2001, 2002) can be succinctly summarized. A resonance instability occurs in the vicinity of the upper hybrid frequency, exciting upper hybrid plasma waves and small scale field-aligned plasma depletions, or striations, which grow nonlinearly, reinforced by self focusing. Also, a parametric instability takes place in the Langmuir resonance region near the pump reflection height, where nonlinear processes in Langmuir turbulence create cavitons which accelerate electrons up to tens of $\mathrm{eV}$ with the help of electron elastic scattering. For launch of high-power HF radio waves sufficiently close to parallel to the magnetic field, the HF propagation path leads to trapping of the HF rays in the striations, which can heat sufficiently to allow the HF energy to bore up to the reflection height. Striations extend along $\boldsymbol{B}$ both above and below the upper hybrid altitude, and as a result nonlinear cavities and cavitons are formed even $20-30 \mathrm{~km}$ from the upper hybrid altitude. HF waves effectively trapped inside cavities lead to additional heating there. The maximum heating is near the magnetic zenith, as is the intensity of HF-enhanced incoherent scatter echoes due to Langmuir waves (as observed by Isham et al., 1999). A significant part of the pump wave effectively trapped inside the cavity reaches the height of reflection, and by electron acceleration produces notable fluxes of accelerated electrons via Langmuir turbulence (Gurevich et al., 2004). The essential factor at these HF launch angles towards magnetic zenith is the trapping of the HF radio waves (Gurevich et al., 2001, 2005), whereby first, a large percent of the total HF energy becomes deposited in the plasma, and second, a significant fraction goes into electron acceleration. Calculations based on this theory have estimated that accelerated electrons can absorb up to tens of percent of the HF ERP (Gurevich et al., 2005). Energy deposition and electron acceleration are intensified for pumping near the double resonance, and electron acceleration is enhanced for operation at multiples of the electron gyro harmonic frequency. We should acknowledge that invoking the above explanations need not exclude other electron acceleration processes from occurring as well. For example, Ashrafi et al. (2007) suggested that upper hybrid waves, which propagate perpendicular to the magnetic field, and Langmuir waves, which propagate parallel to the magnetic field, act simultaneously to accelerate electrons even in the steady state. However the role of Langmuir turbulence near the reflection height in electron acceleration remains central.

On 13 October we observe the increased plasma density, for operation very near the double resonance. We observe the presence of HF-enhanced ion spectra, which indicates that HF pump energy is reaching the reflection height, where Langmuir turbulence can produce fluxes of suprathermal electrons. We are operating very close to the triple of the electron gyro frequency, which should maximize the ef- fectiveness of suprathermal electron flux production. We see plasma density enhancements for which the only explanation we can identify is the ionization by this suprathermal electron flux, and prior calculations verify adequate energy can be available.

Data obtained on 12 October are very similar to the 13 October in terms of its aeronomy and geophysical character. Among with it they show no significant plasma density enhancement, nor any detectable HF-enhanced ion spectra, indicating the absence of strong pump energy reaching the reflection height. Thus there is no such mechanism to produce significant suprathermal electron fluxes. While the days are similar for purposes of examining their aeronomy, they are critically different for purposes of examining their plasma physics. The experiment on 12 October does not have operation very near the double resonance and the third gyro harmonic. On 13 October 2006 the upper hybrid resonance altitude and the altitude of heater-induced Langmuir turbulence was about $230 \mathrm{~km}$, and it did not change during the experiment. At the altitude of $230 \mathrm{~km}$, the pump frequency $f_{H}=4040 \mathrm{kHz}$ is very close to and just below the third electron gyro harmonic, $3 f_{c e}=4045 \mathrm{kHz}$. Therefore, in such conditions one would expect double resonance $\left(f_{H}=f_{\mathrm{UHR}} \approx 3 f_{c e}\right)$ effects to pertain, effects which are important to the magnetic zenith and electron acceleration process (Gurevich et al., 2001, 2004). In contrast, on 12 October 2006 the upper hybrid resonance altitude was about $210 \mathrm{~km}$, where the heater frequency $f_{H}$ was far from $3 f_{c e}=4079 \mathrm{kHz}$.

We have observed an increase in plasma density during a high-power HF experiment pointing towards magnetic zenith. Further, we have examined possible sources for this ionization change, including the publications of Sipler and Biondi (1972) and Meltz and LeLevier (1970) and others since, and find only one that can explain our observations. Carlson (1993) proposed the production of ionization by suprathermal electrons, and presented calculations showing that the observable plasma density enhancements, provided by the efficient conversion of HF energy to the electron flux energy, can occur when enough ERP is transmitted. Gurevich et al. $(2001,2002)$ proposed a magnetic zenith mechanism for making a large fraction of the ERP available in the plasma production region, and means for the electron acceleration. Bernhardt et al. (1989), Djuth et al. (1999, 2005) Pedersen et al. (2003), Gustavsson et al. (2005), Holma et al. (2006), Ashrafi et al. (2007) have also worked on electron acceleration mechanisms and experimental evidence for their presence. Our work here shows the signatures of the magnetic zenith mechanism in terms of both rapid formation of striations and strong Langmuir turbulence when the plasma-density enhancements were produced. We conclude that the proximity to the double resonance and to the multiple gyro frequency pumping is a key to the effectiveness of plasma production through ionization by suprathermal electron fluxes accelerated in the strong Langmuir turbulence region near the pump height of reflection. Our findings should 
stimulate further theoretical development and experimental work.

\section{Concluding remarks}

We have presented the results of our analysis of multiinstrument data from an experiment on 13 October 2006 at the EISCAT/HEATING facility at Troms $\varnothing$, Norway. The experiment was carried out in the evening hours when the electron density in the F-region dropped, and the HF pump frequency $f_{H}$ was near and then above the critical frequency of F2 layer. The distinctive feature of this experiment is that the pump frequency was just below the third electron gyro harmonic frequency while both the HF pump beam and UHF radar beam were directed towards the magnetic zenith (MZ). The results showed the thermal electron excitation of the HFinduced striations as seen simultaneously from HF bi-static scatter and CUTLASS radar observations, accompanied by increases of electron temperature when the heater frequency was near and then above the critical frequency of F2 layer up to $0.4 \mathrm{MHz}$. In addition to strong electron gas heating and plasma structuring, we observed measurable plasma density enhancements on one of two otherwise similar adjacent days. We explain this plasma density increase by building on prior work and taking the double resonance condition to significantly enhance electron acceleration. The increase of the electron density by up to $25 \%$, accompanied by the strong HF-induced electron heating, was only observed when the heater frequency was near the critical frequency and just below the third electron gyro harmonic frequency.

In summary, the combined effect of upper hybrid resonance and gyro resonance at the same altitude gives rise to strong electron heating and excitation of striations, which at magnetic zenith leads to HF ray trapping and extension of HF waves to altitudes where they can excite Langmuir turbulence, leading to fluxes of electrons accelerated to energies that produce measurable ionization.

Acknowledgements. We would like to thank the Director and Staff of the EISCAT Scientific Association for providing the Troms $\varnothing$ heating experiments in conjunction with the EISCAT UHF radar measurements on 12 and 13 October 2006. EISCAT is an International Association supported by Finland (SA), France (CNRS), Germany (MPG), Japan (NIPR), Norway (NFR), Sweden (NFR) and the United Kingdom (PPARC). The work has been supported by the RFBR, grants 07-05-00167, 07-05-13516. Participation by one of us (HCC) was made possible by support from AFOSR.

Topical Editor K. Kauristie thanks two anonymous referees for their help in evaluating this paper.

\section{References}

Ashrafi, M., Kosch, M. J., and Honary, F.: Heater-induced altitude descent of the EISCAT UHF ion line enhancements: Observations and modelling, Adv. Space Res., 38, 2645-2652, 2006.
Ashrafi, M., Kosch, M. J., Kaila, K., and Isham, B.: Spatiotemporal evolution of radio wave pump-indiced ionospheric phenomena near the fourth electron gyroharmonic, J. Geophys. Res., 112, A05314, doi:10.1029/2006JA011938, 2007.

Bernhardt, P., Tepley, C., and Duncan, L.: Airglow enhancements associated with plasma cavities formed during ionospheric heating experiments, J. Geophys. Res., 94, 9071-9092, 1989.

Blagoveshchenskaya, N. F., Borisova, T. D., Kornienko, V. A., et al.: Probing of medium-scale traveling ionospheric disturbances using HF-induced scatter targets, Ann. Geophys., 24, 23332345, 2006a, http://www.ann-geophys.net/24/2333/2006/.

Blagoveshchenskaya, N. F., Borisova, T. D., Kornienko, V. A., Leyser, T. B., Rietveld, M. T., and Thidé, B.: Artificial fieldaligned irregularities in the nightside auroral ionosphere, Adv. Space Res., 38, 2503-2510, 2006b.

Blagoveshchenskaya, N. F., Kornienko, V. A., Brekke, A., Rietveld, M. T., Kosch, M. J., Borisova, T. D., and Krylosov, M. V.: Phenomena observed by HF long-distance tools in the HF modified auroral ionosphere during magnetospheric substorm, Radio Sci., 34, 715-724, 1999.

Brandstrom, B. U. E., Leyser, T. B., Steen, A., Rietveld, M. T., Gustavsson, B., Aso, T., and Ejiri, M.: Unambiguous evidence of HF pump-induced airglow at auroral latitudes, Geophys. Res. Lett., 26, 3561-3564, 1999.

Carlson, H. C.: High power HF modification: Geophysics, span of EM effects, and energy budget, Adv. Space Res., 13, 1015-1024, 1993.

Carlson, H. C.: Insights from Optical emissions, into physics of high power radio wave interactions with plasmas, Proceedings of XXVIIth URSI General Assembly, session GH1, Maastricht, 2002.

Carlson, H., Wickwar, V., and Mantas, G.: Observations of fluxes of suprathermal electrons accelerated by HF excited Langmuir instabilities, J. Atmos. Terr. Phys., 12, 1089-1100, 1982

Djuth, F. T., Jost, R. J., Noble, S. T., Gordon, W. E., Stubbe, P., Kopka, H., Nielsen, E., Bostrøm, R., Derblom, H., Hedberg, A., and Thidé, B.: Observations of $\mathrm{E}$ region irregularities generated at auroral latitudes by a high power radio wave, J. Geophys. Res., 90, 12293-12306, 1985.

Djuth, F. T., Bernhardt, P. A., Tepley, C. A., et al.: Large airglow enhancements produced via wave-plasma interactions in sporadic E, Geophys. Res. Lett., 26, 1557-1560, 1999.

Djuth, F. T., Pedersen, T. R., Gerken, E. A., et al.: Ionospheric modification at twice the electron cyclotron frequency, Phys. Res. Lett., 94, 12501-12504, 2005.

Franz, T. L., Kelley, M. C., and Gurevich, A. V.: Radar backscattering from artificial field-aligned irregularities, Radio Sci., 34, 465-475, 1999.

Grach, S. M. and Trakhtengerts, V. Y.: Parametric excitation of ionospheric irregularities extended along the magnetic field line, Radiophys. Quantum Electron., 18, 951-957, 1976.

Greenwald, R. A., Baker, K. B., Dudeney, J. R., et al.: DARN/SuperDARN: A global view of the dynamics of highlatitude convection, Space Sci. Rev., 71, 761-796, 1995.

Gurevich, A. V., Lukyanov, A. V., and Zybin, K. P.: Stationary state of isolated striations developed during ionospheric modification, Phys. Lett. A., 206, 247-259, 1995.

Gurevich, A. V., Carlson, H., and Zybin, K. P.: Nonlinear structur- 
ing and southward shift of a strongly heated region in ionospheric modification, Phys. Lett. A., 288, 231-239, 2001.

Gurevich, A. V., Zybin, K. P., and Carlson, H.: Magnetic-zenith effect, Phys. Radiophys. Quant. Electron., 48(9), 686-699, 2005 (English Translation).

Gurevich, A., Hagfors, T., Carlson, H., Karashtin, A., and Zybin, K.: Self-oscillations and bunching of striations in ionospheric modifications, Phys. Lett. A., 239, 385-392, 1998.

Gurevich, A., Zybin, K., Carlson, H., and Pedersen, T.: Magnetic zenith effect in ionospheric modifications, Phys. Lett. A, 305, 5, 264-274, 2002.

Gurevich, A. V., Carlson, H. C., Medvedev, Yu. V., and Zybin, K. R.: Langmuir turbulence in ionospheric plasma, Plasma Phys. Rep., 30, 995-1005, 2004.

Gustavsson, B., Sergienko, T., Kosch, M. J., Rietveld, M. T., Steen, A., Brandstrom, B. U. E., Leyser, T. B., Isham, B., Gallop, P., Aso, T., Ejiri, M., Kaila, K., Jussila, J., and Holma, H.: The electron distribution during HF pumping - a picture painted in all colours, Ann. Geophys., 23, 1747-1754, 2005,

http://www.ann-geophys.net/23/1747/2005/.

Gustavsson, B., Leyser, T. B., Kosch, M., Rietveld, M. T., Steen, A., Brandstrom, B. U. E., and Aso, T.: Electron gyroharmonic effects in ionization and electron acceleration during high-frequency pumping in the ionosphere, Phys. Rev. Lett., 97195002, doi:10.1103/PhysRevLett.97.195002, 2006.

Holma, H., Kaila, K. U., Kosch, M. J., and Rietveld, M. T.: Recognizing the blue emission in artifical aurora, Adv. Space. Res., 38, 2653-2658, 2006.

Isham, B., Rietveld, M., Hagfors, T., LaHoz, C., Mishin, E., Kofman, W., Leyser, T., and van Eyken, A.: Aspect angle dependence of HF enhanced incoherent backscatter, Adv. Space Res., 24, 8, 1003-1006, 1999.

Kosch, M., Rietveld, M., Yeoman, T., Cierpka, K., and Hagfors, T.: The high-latitude artificial aurora of 21 February 1999: An analysis, Adv. Polar Upper Atmos. Res., 16, 1-12, 2002.

Lester, M., Chapman, P. J., Cowley, S. W. H., et al.: Stereo CUTLASS: A new capability for the SuperDARN radars, Ann. Geophys., 22, 459-473, 2004, http://www.ann-geophys.net/22/459/2004/.

Leyser, T. B., Brandstrom, B. U. E., Gustavsson, B., Steen, A., Honary, F., Rietveld, M. T., Aso, T., and Ejiri, M.: Simultaneous measurements of high-frequency pump-induced airglow and ionospheric temperatures at auroral latitudes, Adv. Polar Upper Atmos. Res., 14, 1-11, 2000.

Meltz, G. and LeLevier, R. E.: Heating the F Region by Deviative Absorption of Radio Waves, J. Geophys. Res., 75, 6406-6416, 1970.
Milan, S. E., Yeoman, T. K., Lester, M., Thomas, E. C., and Jones, T. B.: Initial backscatter occurrence statistics from the CUTLASS HF radars, Ann. Geophys., 15, 703-718, 1997, http://www.ann-geophys.net/15/703/1997/.

Minkoff, J., Kugelman, P., and Weissman I.: Radio frequency scattering from a heated ionospheric volume, 1, VHF/UHF fieldaligned and plasma-line backscatter measurements, Radio Sci., 9, 941-955, 1974.

Mishin, E. V., Burke, W. J., and Pedersen, T.: On the onset of HF-induced airglow at HAARP, J. Geophys. Res., 109 A02305, doi:10.1029/2003JA010205, 2004.

Mishin, E. V., Burke, W. J., and Pedersen, T.: HF-induced airglow at magnetic zenith: theoretical considerations, Ann. Geophys., 23, 47-53, 2005, http://www.ann-geophys.net/23/47/2005/.

Pedersen, T. and Carlson, H.: First observations of HF heaterproduced airglow at the High Frequency Active Auroral Research Program facility: Thermal excitation and spatial structuring, Radio Sci., 36, 1013-1026, 2001.

Pedersen, T., McCarrick, M., Gerken, E., Selcher, C., Sentman, D., Carlson, H., and Gurevich, A.: Magnetic zenith enhancement of $\mathrm{HF}$ radio-induced airglow production at HAARP, Geophys. Res. Lett., 30, 4, 1169, doi:1029/2002GL016096, 2003.

Rietveld, M. T., Kohl, H., Kopka, H., and Stubbe, P.: Introduction to ionospheric heating at Troms $\varnothing-$ I. Experimental overview, J. Atmos. Terr. Phys., 55, 577-599, 1993.

Rietveld, M. T., Kosch, M. J., Blagoveshchenskaya, N. F., Kornienko, V. A., Leyser, T. B., and Yeoman, T. K.: Ionospheric electron heating, aurora and striations induced by powerful HF radio waves at high latitudes: aspect angle dependence, J. Geophys. Res., 108(A4), 1141, doi:10.1029/2002JA009543, 2003.

Rietveld, M. T., Wright, J. W., Zabotin, N., and Pitteway, M. L. V.: The Troms $\varnothing$ Dynasonde, Polar Science, 2, 1, 55-71, doi:10.1016/j.polar.2008.02.001, 2008.

Rishbeth, H. and van Eyken, T.: EISCAT: Early history and the first ten years of operation, J. Atmos. Terr. Phys., 55, 525-542, 1993.

Robinson, T. R.: The heating of the high latitude ionosphere by high power radio waves, Phys. Rep., 179, 79-209, 1989.

Schunk, R. W. and Nagy, A. F.: Ionospheric physics, plasma physics, and chemistry, Cambridge University Press, 2000.

Sipler, D. P. and Biondi, A.: Measurements of $\mathrm{O}\left({ }^{1} \mathrm{D}\right)$ quenching rates in the F region, J. Geophys. Res., 77, 6202-6218, 1972.

Vas'kov, V. V. and Gurevich, A. V.: Nonlinear resonant instability of a plasma in the field of an ordinary electromagnetic wave, Sov. Phys. JETP, 42, 91-97, 1976 (English Translation). 